\title{
Building Wall Heat Capacity Measurement Through Flux Sensors
}

\section{Roberto Ricciu ${ }^{* 1}$, Alessandra Galatioto ${ }^{2}$, Luigi A. Besalduch ${ }^{3}$, Giuseppe Desogus 4 , Lorenza Di Pilla ${ }^{5}$}

${ }^{1}$ Department of civil engineering, environmental and architecture, University of Cagliari, Cagliari, Italy e-mail: ricciu@unica.it

${ }^{2}$ Department of civil engineering, environmental and architecture, University of Cagliari, Cagliari, Italy e-mail: alessandra.galatioto@unica.it

${ }^{3}$ Department of civil engineering, environmental and architecture, University of Cagliari, Cagliari, Italy e-mail: besalduch@,unica.it

${ }^{4}$ Department of civil engineering, environmental and architecture, University of Cagliari, Cagliari, Italy e-mail: gdesogus@,unica.it

${ }^{5}$ College of Architecture and Design, Al Ghurair University, Dubai International Academic City, Dubai, United Arab Emirates e-mail:1.dipilla@agu.ac.ae

Cite as: Ricciu, R., Galatioto, A., Besalduch, L. A., Desogus, G., Di Pilla, L., Building Wall Heat Capacity Measurement Through Flux Sensors, J. sustain. dev. energy water environ. syst., 7(1), pp 44-56, 2019, DOI: https://doi.org/10.13044/j.sdewes.d6.0234

\begin{abstract}
Thermal comfort and energy saving have become a priority for construction industry professionals. An important parameter of the comfort is the mean radiant temperature and its dependence on the building envelope. In the present research, a dynamic physical model has been studied in a climatic chamber, linked to the specific heat $(C)$, density $(\rho)$ and thermal conductivity $(\lambda)$. The heat capacity is usually quantifiable in small, homogeneous and uniform samples by the application of calorimetric methods. Consequently, the building energy consumption assessed through calorimetric methods, is often quite different from the energy consumption measured in situ. In this work an experimental model for the assessment of specific heat of real-size building components is proposed. Such a parameter was determined by measuring the heat flow through a building wall. The model has been validated by comparing the evaluated properties of known materials for different thermal gaps.
\end{abstract}

\section{KEYWORDS}

Lightweight walls, Specific heat capacity, Climatic chamber, Experimental tests, Physical propriety, Dynamic model, Energy saving.

\section{INTRODUCTION}

The Mediterranean Zone and the other climatic zones ranging between the $45^{\text {th }}$ parallel and the two tropics of Capricorn and Cancer are usually characterized by mild climates. In particular, the more the area is close to the tropics, the more the summers are sunny and solar radiation is severe.

\footnotetext{
${ }^{*}$ Corresponding author
} 
Many methods are studied and applied to energy saving and reduction, such as the better mix of energy retrofit measures for different geographical areas proposed by Di Pilla et al. [1] or an interactive and comprehensive platform based on an advanced metering infrastructure for exchanging information on energy consumption proposed by Podgornik et al. [2] or another aspects linked to the facility considered, classified into the building, energy system, production and logistics proposed by Smolek et al. [3]. Another aspect is related to renewable energies as proposed by Dehghan and Pfeiffer [4]. Hence, if buildings are not properly designed and built, the heat stored in the external envelope during the hot season makes them uncomfortable for occupants and also increasing the Heating, Ventilation and Air Conditioning (HVAC) cost [5]. This is true even in hothumid climates and a subdivision of the contribution to the energy consumption and potential for energy savings of wall and HVAC has also been estimated by Mohammed and Budaiwi [6].

In the light of the above remarks, building design should consider several aspects: the proper orientation and space distribution of the building, the proper ratio of glazing to the opaque wall area, the use of "sun shades" (which are considered to be effective solutions to limit heat gain of a building), etc. The main factors which the present work is dealing with are consequently the thermal properties of opaque and glazed building envelope in dynamic and steady-state regimes.

The use of lightweight materials characterizes an interesting building technology for opaque envelopes and, if prefabricated, such components can speed up the construction process, also reducing the use of heavy building bearing elements [7].

Notwithstanding, these technologies are currently not properly characterized, and in situ, their assembled features are quite different from their electrical circuit analogy model.

International researches are currently focused on the dynamic behaviour of the building components. In particular, Peng et al. worked on in situ measuring method and the test in climatic chamber similar to Peng and $\mathrm{Wu}$, on the thermal resistance of building components [8] or Pia et al. [9, 10], Bouguerra et al. [11] studied experimentally and theoretically the thermal conductivity using the model of Verma et al. based on Ohms law and the calculated values of heat capacity using the enthalpy concept. Ferrari worked to ensure the thermal comfort of the occupants and to keep the energy consumption low with adequate the thermophysical properties of the wall materials [12]. Ghazi proposed a simple method to determine the specific heat capacity of thermal insulation [13] of buildings. For that reason and more, the International Standard Organization (ISO) in 2008 proposed to deal with significant parameters such as periodic thermal transmittance, decrement factor and time lag to the temperature and thermal flux from the two faces of a wall [14].

Commercially, thermal properties are known and certified for a single material and a certain layer of the building walls, while in dealing with the entire wall, use is made of a mathematical model or measured in situ or in climatic chamber [15].

In particular, in order to assess the thermal properties of opaque elements in existing buildings, the only way is trying to characterize them by in situ measurement or, if possible, to reproduce and analyse the masonry in a climatic chamber.

In mild climates, mathematical steady-state models of walls are not useful to properly define building behaviour. The use of dynamic mathematical models working in periodic regime is necessary.

The representative parameters which describe the dynamic behaviour of a building are: thermal conductivity $(\lambda)[\mathrm{W} / \mathrm{mK}]$, density $(\rho)\left[\mathrm{kg} / \mathrm{m}^{3}\right]$ and the specific heat $(C)$ $[\mathrm{J} / \mathrm{kgK}]$.

Input data are not limited to thermal conductivity as in the Standard ISO 10456, but include $\rho$ and $C$ [16]: hence, they have to be correctly assessed. As shown in the 
following, especially the first one needs accurate measurements since literature data are not always matching. Kim et al. [15] and Ficker et al. [17] studied thermal conductivity and specific heat which vary non-linearly with temperature and these two physical properties are correlated as also done in the present work.

In this paper, the temperature and thermal flux measurements are based on the Standard ISO 9869 [18]. The specific heat of a "black box" based envelope are described based on ASTM C 315-82 [19]. They have been carried out by the use of a dedicated climatic chamber based on the Standard EN 1934 [20]. The results are then discussed and presented through an application example.

\section{EXPERIMENTAL SET UP AND ANALYTIC MODEL}

The analysed test wall is representative of an opaque envelope of a newly constructed wall.

In particular, the test wall consists in part of a lightweight self-supporting wall of a residential building, placed in south Sardinia. It is characterized as follows: "EPS 80" panel with density of $15 \mathrm{~kg} / \mathrm{m}^{3}, 12.0 \mathrm{~cm}$ thick, with a grid of 70 metal connectors per $\mathrm{m}^{2}$, $\varnothing 3 \mathrm{~mm}$. The panel is finished with a $2.50 \mathrm{~cm}$ thick of plastering per side with density of $1,500 \mathrm{~kg} / \mathrm{m}^{3}$. Thickness and mass is described in Table 1 .

Table 1. Test wall: thermal and geometric characteristics

\begin{tabular}{cccc}
\hline Component description & $\begin{array}{c}\text { Thermal conductivity } \\
{[\mathrm{W} / \mathrm{mK}]}\end{array}$ & $\begin{array}{c}\text { Thickness } \\
{[\mathrm{mm}]}\end{array}$ & Mass [kg] \\
\hline Lime plaster & 0.54 & 25 & 48 \\
Pre-armed polystyrene plate (EPS 80) & 0.038 & 120 & 2.25 \\
Lime plaster & 0.54 & 25 & 48 \\
& Total (measured) & $170 \pm 2.50$ & $95.38 \pm 1.50$ \\
\hline
\end{tabular}

This building method yields better results since it allows performing opaque "vertical closures" in maximum three-story buildings without using a reinforced concrete structure.

The inertial behaviour of thermal envelope is extremely important, in order to guarantee indoor comfort conditions, without needing to overestimate the cooling system design. For this reason, the physical parameters that dynamically characterize "light elements" in building components have been investigated in the present study.

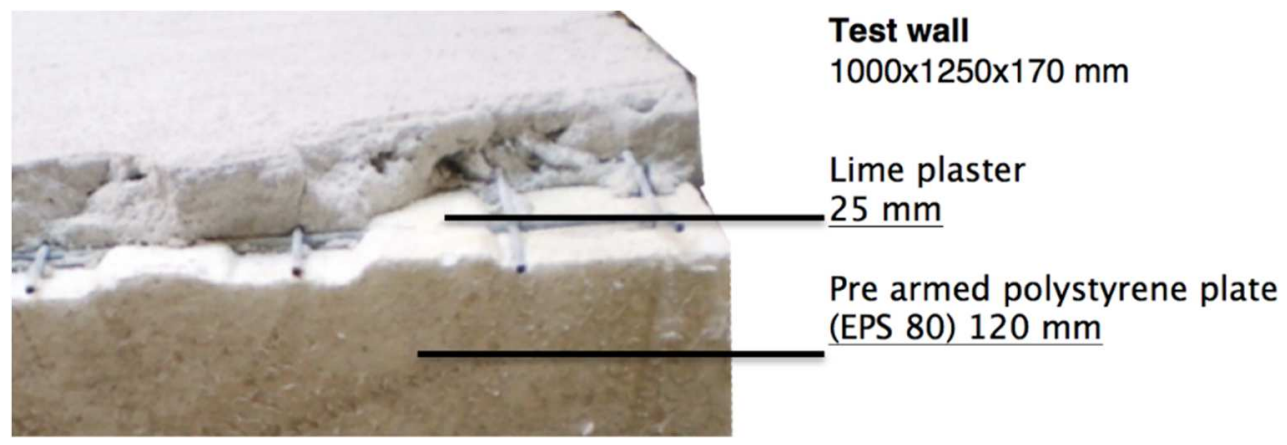

Figure 1. The test wall with its components

The following Table 1 describes the wall sample analysed $(1,000 \times 1,250 \times 170 \mathrm{~mm})$ and its main characteristics.

The specimen was placed in a climatic chamber according to the following scheme in Figure 2. 


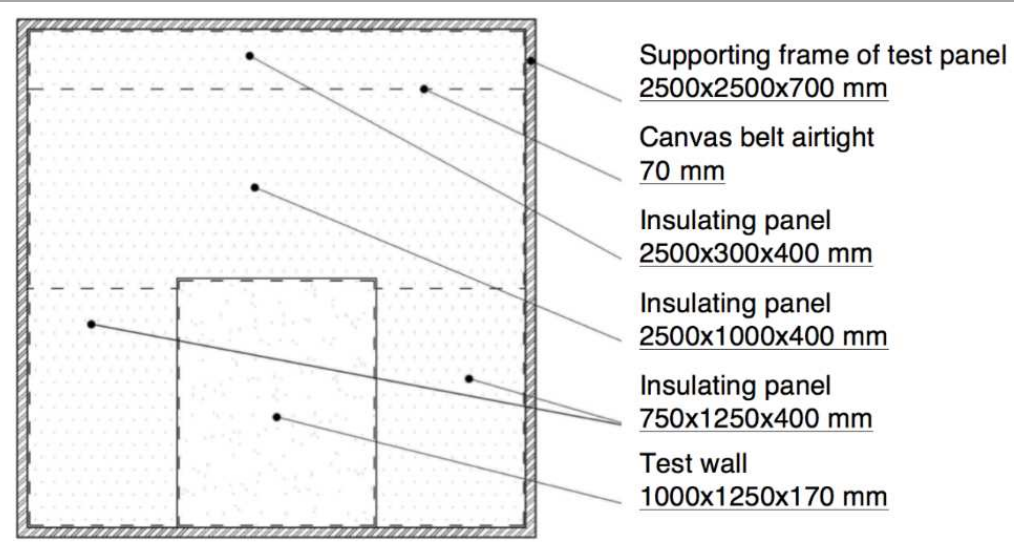

Figure 2. The test wall placed in the climatic chamber support frame

The climatic simulation chamber (Figure 2a) allows testing of full-sized walls with realistic inner and outer climatic conditions [9] and it was designed according to the UNI EN ISO 1934:2000, ISO 9869:1994 and EN 12494:1996. The apparatus consists of two chambers and a frame through which it is possible to measure and control: air temperature, relative humidity and air velocity.

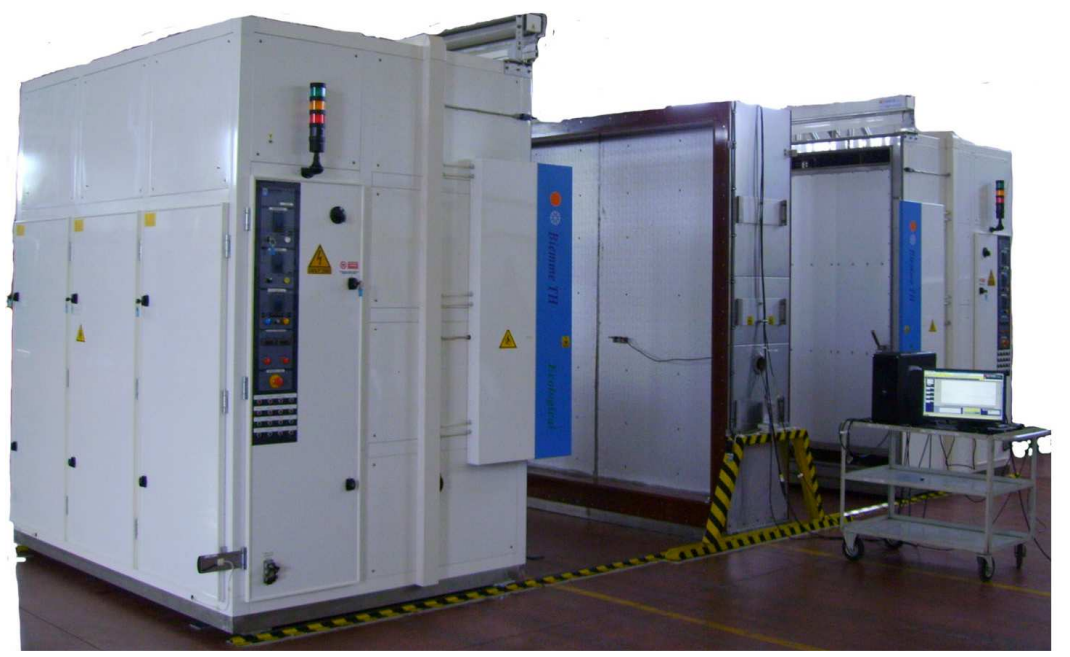

Figure 2a. The climatic chamber used for in this research

The test wall has been built by the use of a dry construction method: such a building technique is being increasingly implemented since it allows accelerating the construction process, while also enhancing and maximizing steady state thermal properties.

The value of thermal transmittance, measured according to Standard ISO 9869, is equal to $0.37 \pm 0.0185 \mathrm{~W} / \mathrm{m}^{2} \mathrm{~K}$ : this value guarantees a high opaque envelope performance level both for a new building and for an existing one in mild climate conditions.

Considering this value, the technical solution implemented allows a suitable level of indoor comfort, with a correct balance between the building-enclosure and the buildingsystem during wintertime. The main task is whether low thermal transmittance values, satisfying the limits prescribed by the current legislation, allow reaching similar values during summertime.

In this case it is necessary to know the dynamic response of the wall system under solar radiation.

In order to assess the specific heat capacity, a large number of methods are currently used. Some of them adopt very small specimens (i.e., calorimetric methods [5]) that are 
not representative of real walls, other ones are based on the Differential Thermal Analysis (DTA) technique [7] or require a complex theoretical analysis for measured data under theoretical boundary conditions [8,11]. Other possible techniques consist in the photothermal, photoacoustic ones [6], or in transient methods which use a Heat Flow Meter (HFM) apparatus [13].

In this paper, a novel and easier method to assess the specific heat of real walls is presented: it implements the use of heat flux meters.

The method consists of submitting the building component at a temperature gap similar to the one naturally occurring during the usual day-night cycles.

For this purpose, it is necessary to expose both the "internal" and "external" faces of the building component to the same temperature.

In situ, this can be obtained for example on a building wall facing north without direct sunshine on its outer part. This would create a considerable temperature difference between its inner and outer part.

In the test room, it is necessary to set both the chambers at the same temperature and then simultaneously setting a temperature difference.

After that, it is necessary to monitor the surface temperature and the heat flow.

In finite terms, the heat exchanged $\Delta Q[\mathrm{~J}]$ can be calculated through the following relation:

$$
\Delta Q=C \times m \times \Delta T
$$

where $C[\mathrm{~J} / \mathrm{kgK}]$ is average specific heat of the building component, $m[\mathrm{~kg}]$ is average mass of the building component and $\Delta T[\mathrm{~K}]$ is variation of temperature.

Four cycles of temperature increase, and three cycles of decrease were performed, as reported in Table 2.

Table 2. Temperature variation during the cycles

\begin{tabular}{ccc}
\hline & Part of the cycle with temperature increase \\
\hline & Initial temperature $\left[{ }^{\circ} \mathrm{C}\right]$ & Final temperature $\left[{ }^{\circ} \mathrm{C}\right]$ \\
\hline 1 & 10 & 40 \\
2 & 10 & 40 \\
3 & 20 & 40 \\
4 & 30 & 40 \\
\hline \multicolumn{3}{c}{ Part of the cycle with temperature decrease } \\
\hline 1 & 40 & 10 \\
2 & 40 & 20 \\
3 & 40 & 30 \\
\hline
\end{tabular}

Technically, they should not be cycles because the variation of the temperature is not constant.

In order to maximize the processing times, the variation of air temperatures in the two shells of climatic chamber was set as the maximum electrical power according to the climatic chamber performance.

The test of the cycle in the ascent or descent regime has been shifted as the two flow measures, from the inside toward the outside and vice-versa were equal to zero: this is because no energy exchange between the hot air of the room and the test wall was identifiable.

In Figure 3a graph of the surface temperature trend of the two wall faces is plotted.

In particular, the first temperature settled was equal to $35^{\circ} \mathrm{C}$ and has been performed in order to allow the wall to reach a constant temperature (null heat flow). 
In the climatic chamber it is also possible to set and control in a dynamic way the air temperature of the volume inside the shell.

The two shells (i.e., chamber 1 and chamber 2) enclosing the space between the bottom of the shell and the test wall create the climatic chamber. In Figure 3, the "Ph" Phases 1 and 2 are characterized by the temperature changes until stationary thermal conditions are reached.

The two shells (i.e., chamber 1 and chamber 2) enclosing the space between the bottom of the shell and the test wall create the climatic chamber. In Figure 3, the "Ph" Phases 1 and 2 are characterized by the temperature changes until stationary thermal conditions are reached.

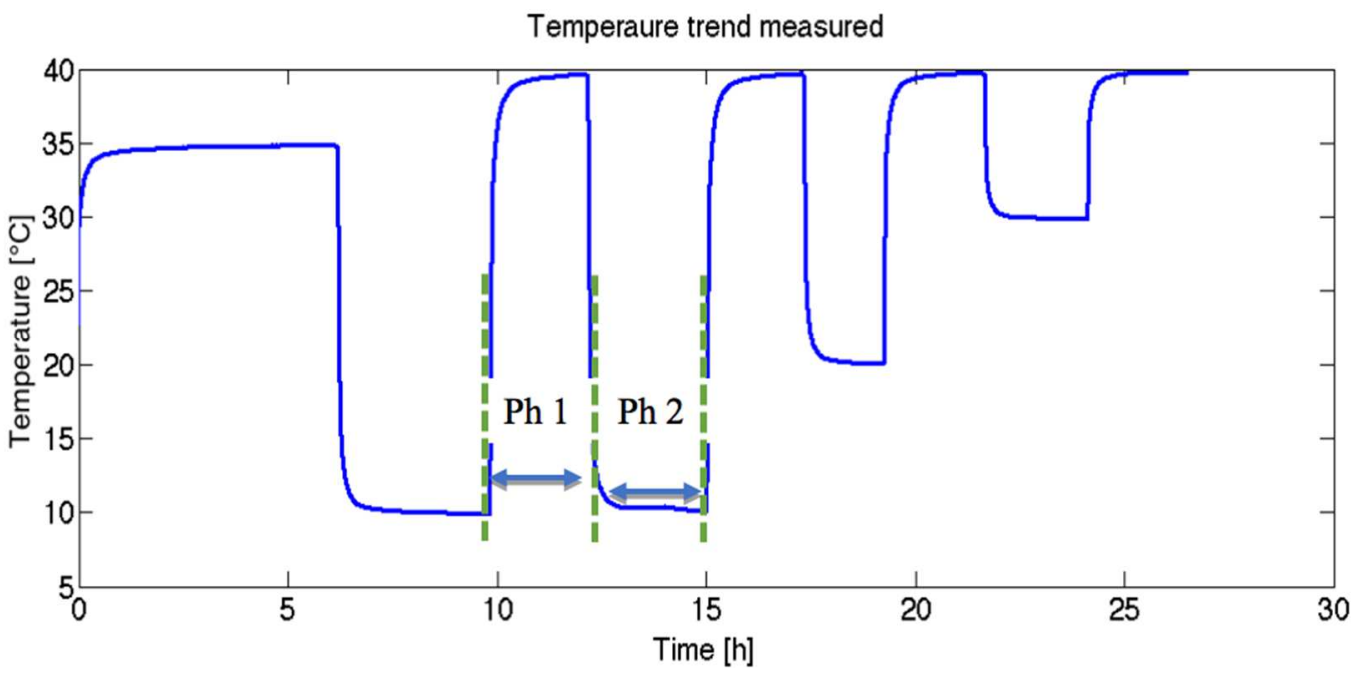

Figure 3. Temperature trend of both the wall faces

The temperature was varied according to the trend reported by the graph in Figure 3 and complying with the values reported in Table 2.

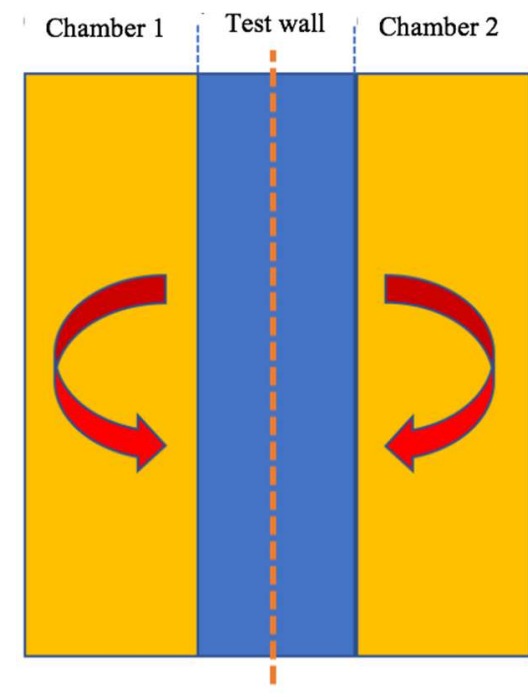

Phase 1

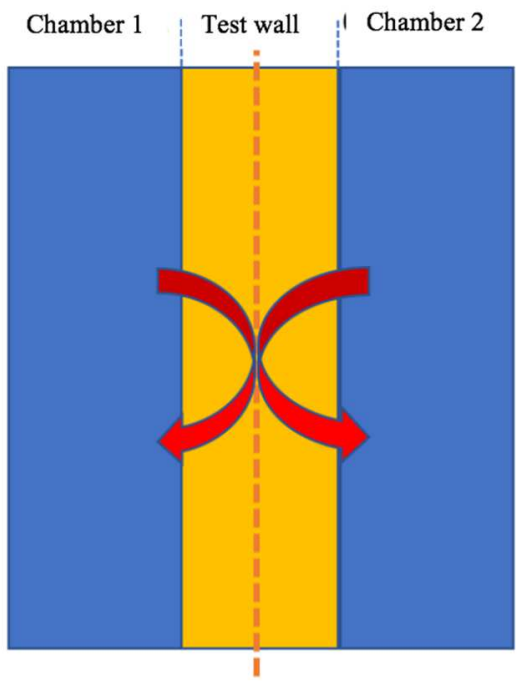

Phase 2

Figure 3a. Heat flux from the indoor air to the test wall (Phase 1) and heat flux from the test specimen to the air in climate chambers (Phase 2)

In the present study the same temperature was settled in both the chambers.

The test wall exchanges heat with the air contained between the two shells as shown by the Figure $3 \mathrm{a}$. 
In the Figure 4 and Figure 5 the test wall (with the monitoring sensors) is shown. In particular, Figure 4 depicts the wall facing the chamber 1, while the Figure 5 shows the wall facing chamber 2 .
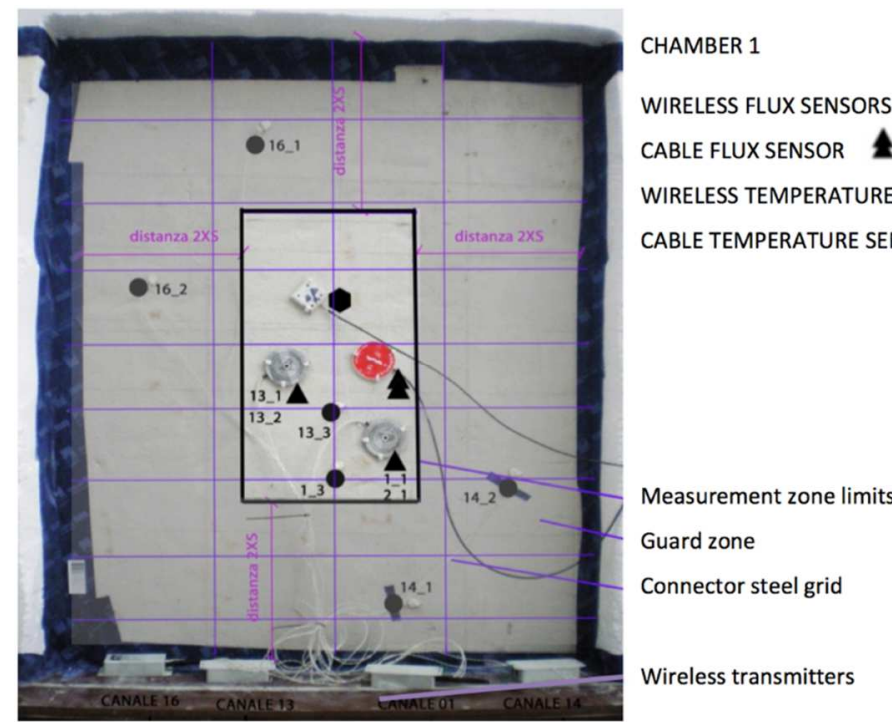

Figure 4. Position of the heat flux sensors and of the RTD in the face 1 (chamber 1)

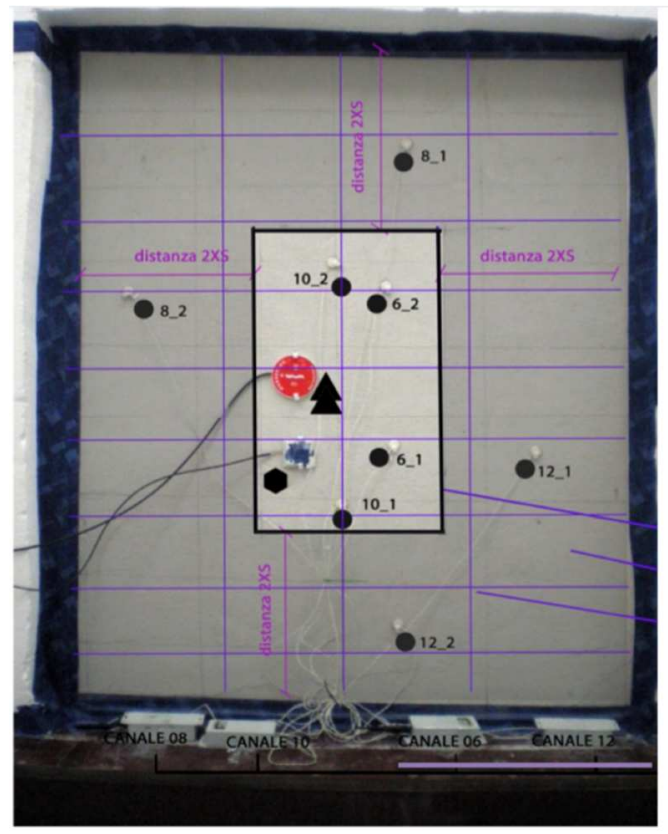

CHAMBER 2

WIRELESS FLUX SENSORS

CABLE FLUX SENSOR

WIRELESS TEMPERATURE SENSORS

CABLE TEMPERATURE SENSOR

Measurement zone limits

Guard zone

Connector steel grid

Wireless transmitters

Figure 5. Position of the heat flux sensors and of the RTD in the face 2 (chamber 2)

The surface temperatures of the two faces of the test wall was measured. Moreover, the two heat flows from side 1 to side 2 and vice-versa were assessed.

The test wall nominal dimensions are: $1,000 \times 1,250 \times 170 \mathrm{~mm}$.

The test wall mass is: $95.38 \pm 1.50 \mathrm{~kg}$.

The graph in Figure 6 shows the heat flow trend over the time of the test. In the same graph, the pattern of the heat flux (in blue) is compared with the temperature trend (green). The temperature trend is shown out of scale.

Through the measuring instrumentation (as shown in Figure 4 and Figure 5) the following values were acquired:

- Temperatures of the wall surfaces; 
- Heat flow (monodimensional 1-D).

The acquisition frequency is equal to $10^{-1} \mathrm{~Hz}$.

The heat flux meter consists of:

- Wireless sensors;

- Four sensors of RTD 1000 thermal measurement in Class 1/3 B by Standard DIN/IEC75. The external surface finishing of the sensors is similar to the plaster in order to have a similar absorption coefficient of solar radiation. The wiring to the radio modem consists of wave electrical wire to minimize the electromagnetic interference;

- The heat flux sensor is the FE01-3B model. The primary sensing element is a cylindrical thermopile sensor. The contact surface has an $80 \mathrm{~mm}$ radius and the thickness is $5.5 \mathrm{~mm}$. The main metrological characteristics are: span (measurement field): -300 to $300 \mathrm{~W} / \mathrm{m}^{2}$, resolution $0.01 \mathrm{~W} / \mathrm{m}^{2}$, unbias: $\pm 5 \%$;

- Cable sensors;

- Two RTD 1000 thermal measurement in Class 1/3 B by Standard DIN/IEC75;

○ Two heat flux sensors of the HFP01 model by Hukseflux. The primary sensing element is a cylindrical thermopile sensor. The contact surface has an $80 \mathrm{~mm}$ radius and the thickness of $5.5 \mathrm{~mm}$.

Multiple sensors (similar for cable and wireless) were installed in order to improve the measurements through statistical analysis.

The measurement chain is completed by a National Instruments USB 6221 and Matlab script acquisition system.

All the equipments are certified by the Italian Calibration Service (SIT).

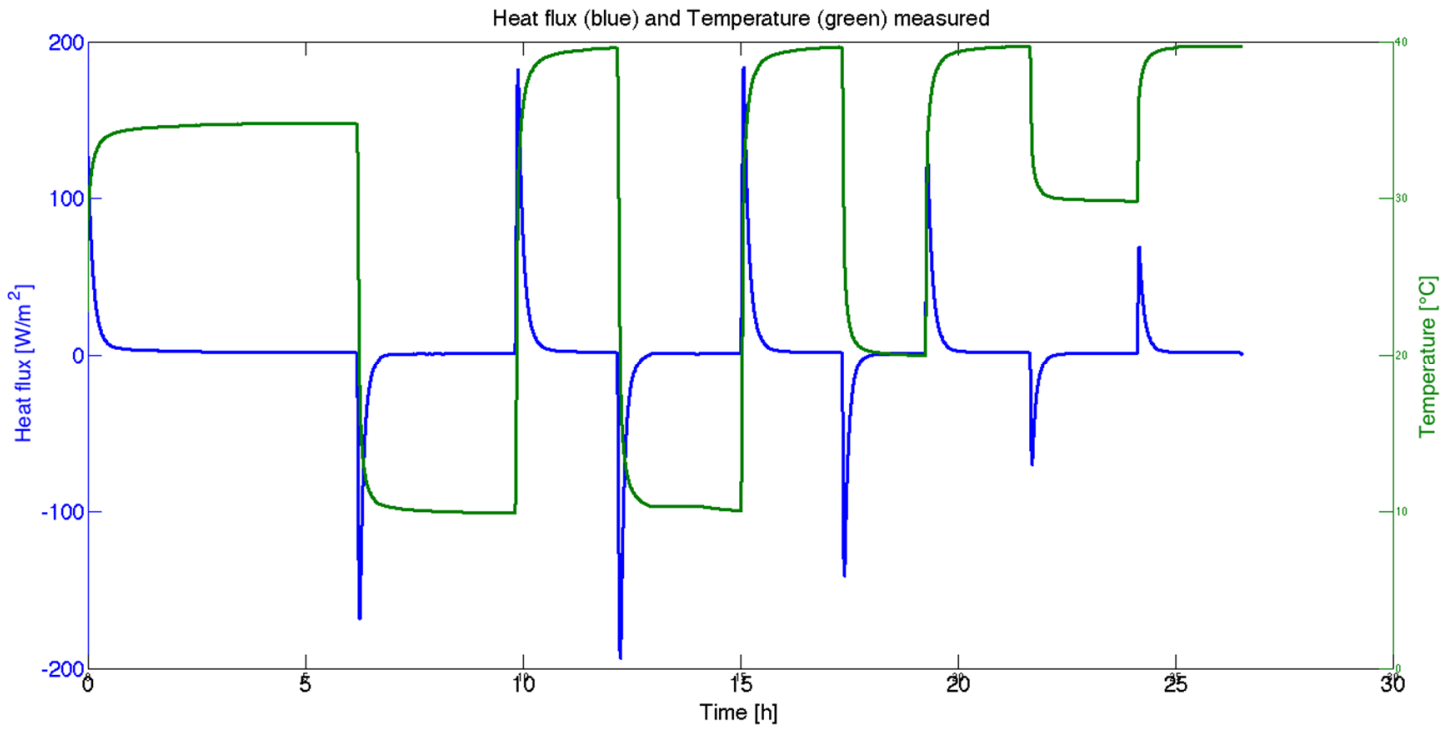

Figure 6. Heat flux and temperature trends measured in the test wall (side 1)

\section{EXPERIMENTAL RESULTS}

The most relevant results are presented below.

In Figure 6, an example of recorded heat flux and temperature in the climatic chambers is shown.

By applying a median filter to the fluximetric data signal, both the energy released from the air to the test wall (in the case of a temperature increase) and the energy subtracted from the air to the test specimen (in the case of a temperature decrease) have been calculated.

In Figure 7, the heat flow trend corresponding to the thermal forcing associated with an air temperature variation from $40{ }^{\circ} \mathrm{C}$ to $30^{\circ} \mathrm{C}$ is plotted. 
The energy $[\mathrm{J}]$, absorbed or released from the wall during the tests is calculated, as described in Table 2.

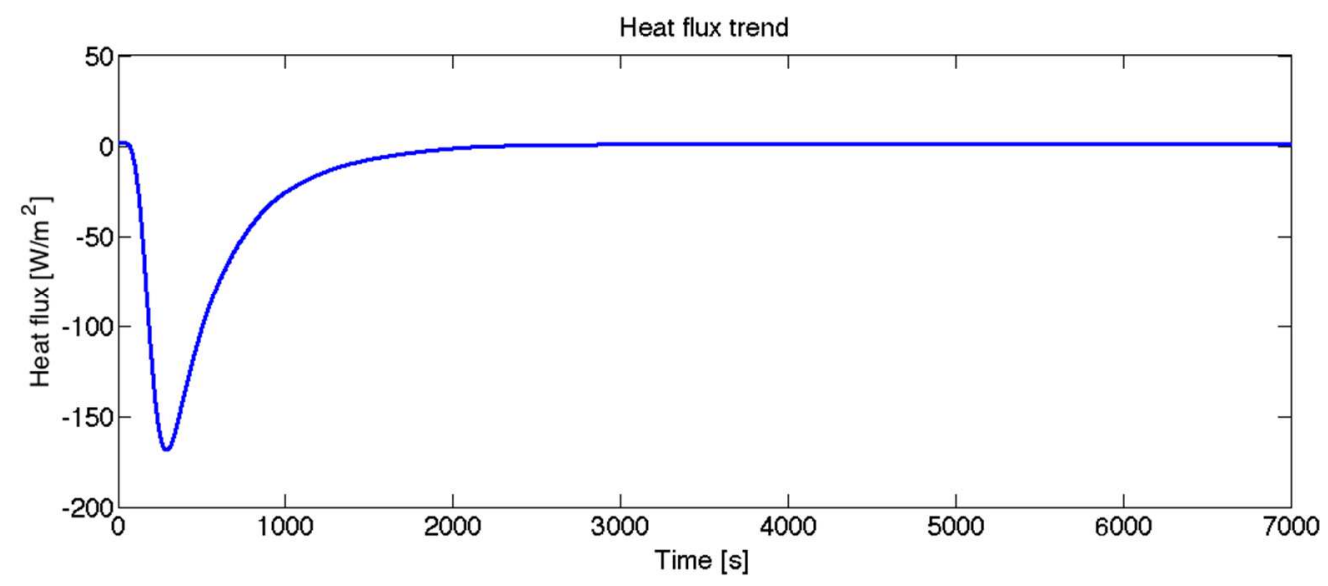

Figure 7. Example of a specific heat flux $(q)\left[\mathrm{W} / \mathrm{m}^{2}\right]$ trend

Due to the geometry of the system and the method of measurement, eq. (1) in infinitesimal terms has turned into eq. (2).

In the calculation, the following equation [coming from eq. (1)] is applied:

$$
C=\frac{\int q_{1} d t+\int q_{2} d t}{m \times \Delta T}
$$

where $q_{1}[\mathrm{~W}]$ is the heat flux, $Q_{1}=\int q_{1} d t[\mathrm{~J}]$ is the energy absorbed or released by the chamber 1 in Figure 3a, $q_{2}[\mathrm{~W}]$ is the heat flux, $Q_{2}=\int q_{2} d t[\mathrm{~J}]$ is the energy absorbed or released from the chamber 2 in Figure $3 a$ and $t$ is the time.

If the energy exchanged by the wall and the air in the climatic chambers is symmetrical to the dashed orange line in Figure 3a is symmetric, it is possible to write:

$$
C=\frac{2 \int Q d t}{m \times \Delta T}
$$

The values obtained during the tests are reported in Table 3.

Table 3. Specific heat $(C)$ associated to the test numbers

\begin{tabular}{cccc}
\hline Test No. & {$[\mathrm{kJ} / \mathrm{kgK}]$} & {$[\mathrm{kJ} / \mathrm{kgK}]$} & Temp. $\left[{ }^{\circ} \mathrm{C}\right]$ \\
\hline 1 & 0.94 & \pm 0.093 & $10->40$ \\
2 & 0.94 & \pm 0.093 & $40->10$ \\
3 & 0.93 & \pm 0.093 & $10->40$ \\
4 & 0.88 & \pm 0.093 & $40->20$ \\
5 & 0.87 & \pm 0.093 & $20->40$ \\
6 & 0.84 & \pm 0.093 & $40->30$ \\
7 & 0.83 & \pm 0.093 & $30->40$ \\
\hline
\end{tabular}

It can therefore be stated that the method provides interesting results able to infer building properties variation according to the average thermal gap.

The Table 3 shows the specific heat trend based on the thermal gap. 
In particular it is important to note that the accuracy associated with the average value of the specific heat has been assessed according to G.U.M. [21] through the methodology of propagation of the uncertainty with $95 \%$ of the coverage factor.

Such values decrease as a function of the average temperature test gap.

This fact seems to be generally consistent with the results reported in other similar researches [22].

According to the analysis of the above data, it is possible to state the following considerations:

- The standard deviation of the first three tests characterized by the same temperatures gap $\left(10-40{ }^{\circ} \mathrm{C}\right)$ is about $0.66 \%$, with an average heat capacity value of $0.934 \mathrm{~kJ} / \mathrm{kgK}$;

- The difference between the average value of the first three tests and the average of the tests 4 and $5\left(20-40{ }^{\circ} \mathrm{C}\right)$ is about $6.5 \%$;

- The difference between the average value of the first three tests and the average of the tests 6 and $7\left(30-40{ }^{\circ} \mathrm{C}\right)$ is about $11.0 \%$.

Now, considering $C[\mathrm{~kJ}]$ as the stored heat for each kilogram of mass and for each kelvin of temperature variation, as well as Berardi and Naldi [23] and Beraldi et al. [24] who analyze the trend of thermal conductivity when the temperature of the building component changes, also the thermal capacity $C$ in this work is not constant when the average wall temperature changes.

In particular, there is a linear trend in the chosen working range $\left(10-40{ }^{\circ} \mathrm{C}\right)$, the decrease of $C$ with an increase in the average wall temperature (Figure 8). In Figure 8, the trend of the specific heat $C$ to the 3 points is shown. The average value of the first 3 tests are shown in Table 3, average value of the test N.4 and 5, the average value of the test N.6 and 7 vs. temperature variation.

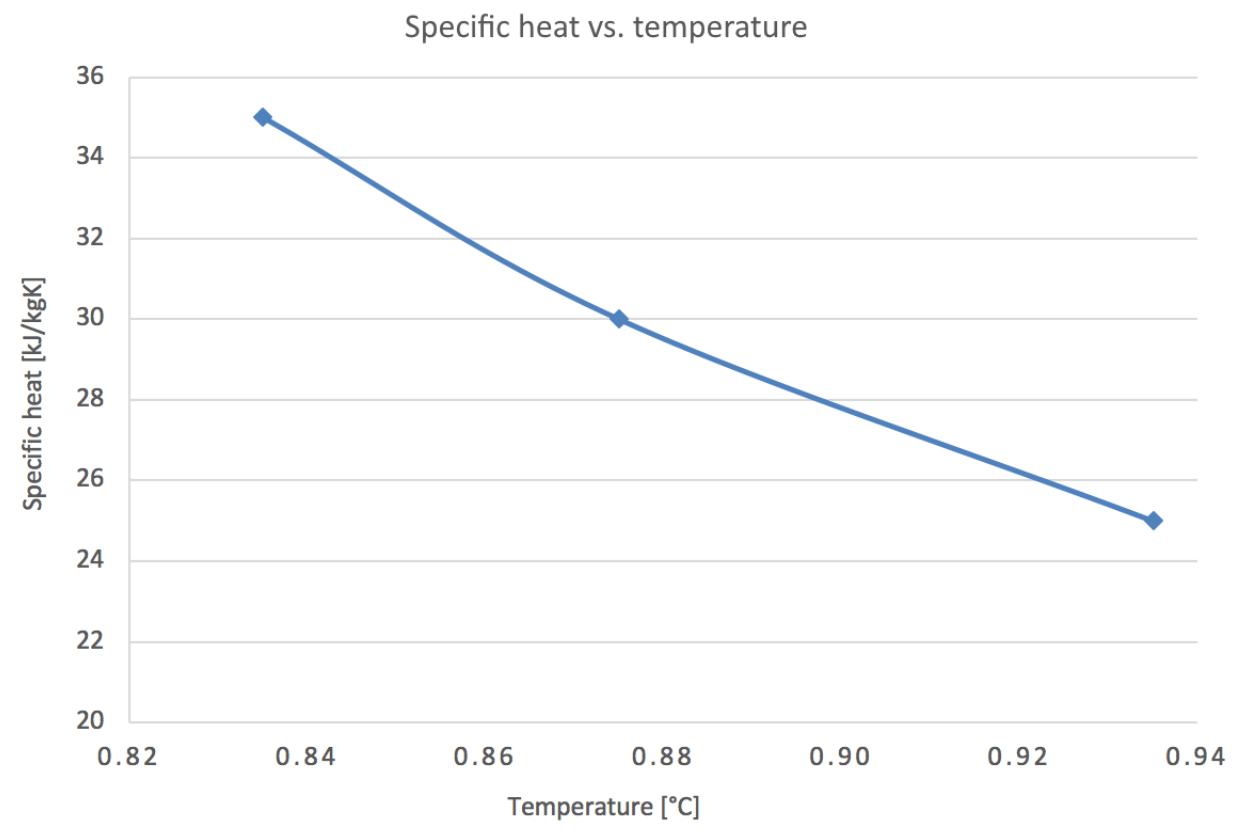

Figure 8. Specific heat vs. temperature

In the works recently proposed by Berardi $[23,24]$ there is an increase (compared to the tabular value) of the thermal conductivity $[\mathrm{W} / \mathrm{mK}]$ with the increase of the temperature starting from the room temperature of $20^{\circ} \mathrm{C}$.

Therefore, if the wall was made of only the same insulating material as those studied by Berardi, an increase in stored heat $(C)[\mathrm{J}]$ would be expected with an increase in the average temperature. 
In fact, an increase in the thermal conductivity leads to an increase in the specific thermal flow $\left[\mathrm{W} / \mathrm{m}^{2}\right]$ and in the application of the eq. (2), also of the thermal conductivity $C[\mathrm{~W} / \mathrm{kgK}]$.

The case presented here is in contrast with the data obtained by Berardi because according to what is shown in Table 3, when the average wall temperature varies, instead of having an increase, its value decreases. Actually, in the tested wall, the thermal storage capacity is borne by the concrete, whose density represents $95 \%$ of the total mass of the wall.

Moreover, the thermal conductivity of the concrete, as also shown by recent studies [25-27], dealing with the same temperature range studied in this work unlike the insulating materials studied by Berardi, decreases with increasing temperature almost in all temperature ranges. In this work, the decrease in thermal conductivity is up to $36 \%$ in a temperature range from 0 to $1,000{ }^{\circ} \mathrm{C}$ [26].

It can therefore be stated that the method provides interesting results, since it is able to determine specific heat of building components by means of climatic chamber tests and in situ measuring campaigns, without a previous knowledge of their single components (layers).

\section{CONCLUSIONS}

The present work deals with an experimental test on light wall, whose components' thermal dynamic properties are unknown.

The tests were run in a climatic chamber, but it would not be difficult repeating them, for example, in a real building.

Through the relationship that relates heat exchange $[\Delta Q$, obtained by eq. (2) by means of the direct measurement of the heat flow meters], temperature variation $(\Delta T$, measured by temperature sensors in the two faces of the wall) and mass ( $m$, measured in a laboratory scale), actually the specific heat $(C)$ can be obtained from eq. (2).

The trend of the specific heat vs. temperature in the tested wall and environmental boundary conditions is negative.

Therefore, knowing the specific heat $(C)$ of a wall "black box", it is possible to infer and quantify the performance improvement associated with different insulation systems, both in steady-state and in dynamic regime.

\section{ACKNOWLEDGMENT}

The authors wish to thank all the system+staff (in particular Ing. Matteo Racheli for his economic contribution and technical support) and Immobiliare M.R.D. staff (in particular Mr. Michele Mereu for the specimen set-up). The testing apparatus was financed by Sardinian Regional Government as part of the POLILAB project.

\section{REFERENCES}

1. Di Pilla, L., Desogus, G., Mura, S., Ricciu, R. and Di Francesco, M., Optimizing the Distribution of Italian Building Energy Retrofit Incentives with Linear Programming, Energy and Buildings, Vol. 112, pp 21-27, 2016, https://doi.org/10.1016/j.enbuild.2015.11.050

2. Podgornik, A., Subic, B. and Urosevic, L., The Concept of an Interactive Platform for Real Time Energy Consumption Analysis in a Complex Urban Environment, Journal of Sustainable Development of Energy, Water and Environment Systems, Vol. 3, No. 1, pp 79-94, 2015, https://doi.org/10.13044/j.sdewes.2015.03.0006

3. Smolek, P., Leobner, I., Gourlis, G., Mörzinger, B., Heinzl, B. and Ponweiser, K., Hybrid Building Performance Simulation Models for Industrial Energy Efficiency 
Applications, Journal of Sustainable Development of Energy, Water and Environment Systems, Vol. 6, No. 2, pp 381-393, 2018, https://doi.org/10.13044/j.sdewes.d6.0194

4. Dehghan, M. and Pfeiffer, C., Modelling and Control of Collecting Solar Energy for Heating Houses in Norway, Journal of Sustainable Development of Energy, Water and Environment Systems, Vol. 5, No. 3, pp 359-376, 2017, https://doi.org/10.13044/j.sdewes.d5.0147

5. Desogus, G., Di Benedetto, S. and Ricciu, R., The use of Adaptive Thermal Comfort Models to Evaluate the Summer Performance of a Mediterranean Earth Building, Energy and Buildings, Vol. 104, pp 350-359, 2015, https://doi.org/10.1016/j.enbuild.2015.07.020

6. Mohammed, M. A. and Budaiwi, I. M., Strategies for Reducing Energy Consumption in a Student Cafeteria in a Hot-humid Climate: A Case Study, Journal of Sustainable Development of Energy, Water and Environment Systems, Vol. 1, No. 1, pp 14-26, 2013 , https://doi.org/10.13044/j.sdewes.2013.01.0002

7. European Parliament, European Directive 2010/31/EU on the Energy Performance of Buildings, Official Journal of the European Union Belgium, pp 13-35, 2010.

8. Peng, C. and Wu, Z., In Situ Measuring and Evaluating the Thermal Resistance of Building Construction, Energy and Buildings, Vol. 40, No. 11, pp 2076-2082, 2008, https://doi.org/10.1016/j.enbuild.2008.05.012

9. Pia, G., Casnedi, L., Ricciu, R., Besalduch, L. A., Cocco, O., Murru, A., Meloni, P. and Sanna, U., Thermal Properties of Porous Stones in Cultural Heritage: Experimental Findings and Predictions using an Intermingled Fractal Units Model, Energy and Buildings, Vol. 118, pp 232-239, 2016, https://doi.org/10.1016/j.enbuild.2016.03.011

10. Pia, G., Casnedi, M. L., Ricciu, R., Besalduch, L. A., Baccoli, R., Mastino, C. C., Innamorati, R., Murru, A., Cocco, O., Meloni, P. and Sanna, U., Application of a Novel Method for a Simulation of Conductivity of a Building Material in a Climatic Chamber, Energy Procedia, Vol. 81, pp 995-1004, 2015, https://doi.org/10.1016/j.egypro.2015.12.158

11. Bouguerra, A., Ait-Mokhtar, A., Amiri, O. and Diop, M. B., Measurement of Thermal Conductivity Thermal Diffusivity and Heat Capacity of Highly Porous Building Materials using Transient Plane Source Technique, Int. Comm. Heat Mass Transfer, Vol. 28, No. 8, pp 1065-1078, 2001, https://doi.org/10.1016/S0735-1933(01)00310-4

12. Ferrari, S. and Zanotto, V., The Thermal Performance of Walls under Actual Service Conditions: Evaluating the Results of Climatic Chamber Tests, Construction and Building Materials, Vol. 43, pp 309-316, 2013, https://doi.org/10.1016/j.conbuildmat.2013.02.056

13. Ghazi Wakili, K. B. and Binder, R. V., A Simple Method to Determine the Specific Heat Capacity of Thermal Insulation used in Building Construction, Energy and Building, Vol. 35, No. 4, pp 413-415, 2003, https://doi.org/10.1016/S0378-7788(02)00112-3

14. International Standard Organization, Standard ISO 13786, Thermal Performance of Building Components, Dynamic Thermal Characteristics, Calculation Methods, 2008.

15. Kim, S., Chung, B-J., Kim, M. C. and Kim, K. Y., Inverse Estimation of Temperaturedependent Thermal Conductivity and Heat Capacity Per Unit Volume with the Direct Integration Approach, Numerical Heat Transfer: Part A: Applications, Vol. 44, No. 5, pp 521-535, 2011, https://doi.org/10.1080/713838252

16. ISO 10456:2007, Building Materials and Products -- Hygrothermal Properties -Tabulated Design Values and Procedures for Determining Declared and Design Thermal Values, 2007.

17. Ficker, T., Myslín, J. and Podešvová, Z., Non-linear Temperature Profiles, Acta Polytechnica, Vol. 41, No. 6, pp 66-68, 2001.

18. International Standard Organization, Standard ISO 9869, Thermal Insulation - Building Elements - In Situ Measurement of Thermal Resistance and Thermal Transmittance, 1994. 
19. ASTM International, Standard ASTM C 351-82, Standard Test Method for Mean Specific Heat of Thermal Insulation, West Conshohocken, PA, USA, 1982.

20. European Committee for Standardization, Standard EN 1934, Determination of Thermal Resistance by Hot Box Method using Heat Flow Meter, 2000.

21. UNI CEI ENV 13005, Guide to the Expression of Uncertainty in Measurement (GUM), 2000.

22. Pavlíková, M., Pernicová, R. and Pavlík, Z., Thermophysical Properties of Hydrophobised Lime Plaster - Experimental Analysis of Moisture Effect, AIP Conference Proceedings, Terchova, Slovakia, 2016, https://doi.org/10.1063/1.4955253

23. Berardi, U. and Naldi, M., The Impact of the Temperature Dependent Thermal Conductivity of Insulating Materials on the Effective Building Envelope Performance, Energy and Buildings, Vol. 144, pp 262-275, 2017, https://doi.org/10.1016/j.enbuild.2017.03.052

24. Berardi, U., Tronchin, L., Manfren, M. and Nastasi, B., On the Effects of Variation of Thermal Conductivity in Buildings in the Italian Construction Sector, Energies, Vol. 11, No. 4, p 18, 2018, https://doi.org/10.3390/en11040872

25. Zhang, Y., Sun, Q. and Yang, X., Changes in Color and Thermal Properties of Fly Ash Cement Mortar after Heat Treatment, Construction and Building Materials, Vol. 165, pp 72-81, 2018, https://doi.org/10.1016/j.conbuildmat.2018.01.029

26. Lo Frano, R., Maggini, A. and Aquaro, D., Experimental Thermal Characterization of Concrete to be used in CP5.2 Packaging System, Journal of Physics Conference Series, Vol. 796, No. 1, pp 1-30, 2017, https://doi.org/10.1088/1742-6596/796/1/012048

27. Vodak, F., Černý, R., Drchalová, J., Hošková, Š., Kapičková, O., Michalko, O., Semerák, P. and Toman, J., Thermophysical Properties of Concrete, Cement and Concrete Research, Vol. 27, No. 3, pp 415-426, 1997, https://doi.org/10.1016/S00088846(97)00033-1 